\title{
ACHILLE BASSI E OS ELEMENTOS CONTRIBUINTES À INSTITUCIONALIZAÇÃO DA MATEMÁTICA NO ENSINO SUPERIOR BRASILEIRO
}

\author{
Aline Leme da Silva \\ SESI-Brasil \\ Márcia Helena Alvim \\ Universidade Federal do $A B C-U F A B C$ - Brasil \\ (aceito para publicação em dezembro de 2018)
}

\begin{abstract}
Resumo
Neste artigo iremos buscar compreender as relações desenvolvidas entre a Universidade do Brasil e a Universidade de São Paulo (campus de São Carlos) por meio da atuação do matemático Achille Bassi e, desta forma, refletir sobre alguns elementos contribuintes ao processo de institucionalização da Matemática no Ensino Superior brasileiro. Para isso, nos deteremos resumidamente à biografia do personagem e ao contexto do processo de criação das duas Instituições de Ensino: a Faculdade Nacional de Filosofia (FNFi), integrante da Universidade do Brasil (UB), fundada em 1939 no Rio de Janeiro; e a Universidade de São Paulo (USP) criada em 1934 e expandida para o interior paulista, especificamente para São Carlos, com a criação da Escola de Engenharia de São Carlos (EESC) em 1953. A pesquisa baseada na análise de fontes documentais do acervo de Achille Bassi e da EESC discutiu o processo inicial de institucionalização da Matemática em São Paulo, sinalizando para a importância da circulação de conhecimentos e matemáticos europeus na implantação destas instituições brasileiras.
\end{abstract}

Palavras-chave: Institucionalização da Matemática, História da Matemática, Achille Bassi.

\section{[ACHILLE BASSI AND THE ELEMENTS THAT CONTRIBUTED FOR THE INSTITUTIONALIZATION OF THE MATHEMATICS IN THE BRAZILIAN HIGHER EDUCATION]}

\begin{abstract}
The focus of this article is to understand the relations between the University of Brazil and the University of São Paulo (Campus of São Carlos), through the research and work of the mathematician Achille Bassi, discussing the elements that to contributed for the process of
\end{abstract}


institutionalization of the Mathematical knowledge in the Higher education in Brazil. In this way, we consider a short biograpy of the character and the context of creating the both teaching institutions: the National Faculty of Philosophy (FNFi), part of the University of Brazil (UB), founded in 1939 in Rio de Janeiro; and the University of São Paulo (USP) founded in 1934 and expanded to the interior of São Paulo, specifically for São Carlos, with the creation of the School of Engineering of São Carlos (EESC) in 1953. The research based on the analyses of sources documentaries from Achille Bassi collected at EESC that discuss the initial process of institutionalization of Mathematics in São Paulo. The principal research results is the valorizantion of the importance of the circulation of European knowledge and their mathematicians in the institucionalization of this knowledge in the process of implementation of these two universities.

Keywords: Mathematics institucionalization; History of Mathematics; Achille Bassi.

\section{Introdução}

Neste estudo objetiva-se compreender as relações desenvolvidas entre a Universidade do Brasil e a Universidade de São Paulo (campus de São Carlos) por meio da atuação do matemático Achille Bassi e, desta forma, refletir sobre alguns elementos contribuintes ao processo de institucionalização da Matemática no Ensino Superior brasileiro. Para isso, nos deteremos, resumidamente, em aspectos da biografia do personagem e ao contexto do processo de criação das duas Instituições de Ensino aqui analisadas: a Faculdade Nacional de Filosofia (FNFi), integrante da Universidade do Brasil (UB), fundada em 1939 no Rio de Janeiro; e a Universidade de São Paulo (USP) criada em 1934 e expandida para o interior paulista, especificamente para São Carlos, com a criação da Escola de Engenharia de São Carlos (EESC) que deu início às suas atividades no ano de 1953.

Ao discorrer sobre o tema da institucionalização da matemática, é necessário, primeiramente, definir quais são os pilares de sustentação da institucionalização de qualquer área do conhecimento, sendo estes, "[...] ensino, pesquisa, divulgação e aplicação do conhecimento" (GOLDFARB; FERRAZ, 2002 apud BELTRAN et al, 2014, p. 13). Assim sendo, neste artigo, nos referiremos a alguns caminhos percorridos até que a matemática fosse considerada institucionalizada em solo brasileiro, através da contribuição e trajetória de algumas personalidades e instituições que convergiram para tal fim.

Deve-se ressaltar que, em países como o Brasil, que tiveram seu desenvolvimento histórico vinculado as relações travadas entre europeus, indígenas sul-americanos e africanos, o conceito de ciências deve ser "[...] pensado também como uma das manifestações do conjunto que constitui a história própria desses países, no processo de construção de suas identidades culturais" (DANTES; HAMBURGER, 1996, p. 16). Desta forma, compreendemos o conceito de ciência como Dantes e Hamburger (1996, p. 16): 
"Consideramos que as possibilidades de análise historiográfica se ampliam se conceituarmos a ciência como uma prática de produção de conhecimentos e aplicação de resultados que se estabelece, através de indivíduos que a realizam, como síntese de suas tradições formadoras, com características locais, em determinados meios sociais".

Esta mesma visão também é defendida por Dominique Pestre ao definir a ciência como "[...] uma atividade coletiva, uma atividade organizada em locais e através de instituições" (PESTRE, 1996, p. 38).

Logo, ao estudarmos a história da institucionalização da Ciência, estaremos procurando compreender a cultura científica brasileira, porém, sem analisar ou elencar o que falta para o país atingir tal desenvolvimento, mas levando em consideração o nosso passado, nossa herança colonial e também a "transmissão" e adaptação da ciência europeia no Brasil (VERGARA, 2004, p. 30), através da circulação deste conhecimento em meados dos século XX em São Paulo.

Após apresentarmos esta análise introdutória sobre o conceito de Ciência, iremos nos deter em uma breve biografia do professor Achille Bassi buscando ressaltar sua relevância profissional na instituicionalização da matemática no cenário acadêmico brasileiro do início do século XX.

\section{Biografia de Achille Bassi}

Ao tratarmos de Achille Bassi e do contexto no qual estava inserido, não conseguimos nos separar de uma biografia deste personagem da História da Matemática brasileira. Nas palavras de Videira, a biografia científica tem diferentes objetivos dentre os quais analisar a "atuação como administrador científico, professor e formador de outros cientistas" (VIDEIRA, 2007, p. 145) que vai de encontro com a atuação de Bassi no Brasil.

O matemático ora citado, nasceu no ano de 1907 em Mondovi, Itália, e concluiu seus estudos matemáticos na Escola Normal Superior de Pisa no ano de 1929. Após passar por algumas instituições italianas e americanas, no ano de 1939 foi convidado pelo governo brasileiro para reger a cadeira de Geometria Superior na Faculdade Nacional de Filosofia (FNFi), integrante da Universidade do Brasil (UB).

Ao aceitar o convite e desembarcar no Rio de Janeiro, a partir do ano de 1941 ficou responsável pelas cadeiras de Geometria Superior e Complementos de Geometria (FÁVERO et al, 1991, p. 66). Entretanto, a entrada do Brasil na Segunda Guerra Mundial, em 1942, lutando a favor dos países aliados, contra a Itália, prejudicou os professores italianos que aqui residiam. Pois, todos os contratos dos mesmos com a FNFi foram rescindidos. Segundo Circe Mary Silva da Silva (2002, p. 117), a partir do dia 15 de junho de 1942 nenhum nome de professor italiano constava mais nas Atas da Congregação da Faculdade Nacional de Filosofia do Rio de Janeiro.

Durante esse período Bassi enviou algumas cartas ao ministro Gustavo Capanema Filho (1900-1985), então ministro da Educação e Saúde ${ }^{1}$, relatando a situação em que se

\footnotetext{
${ }^{1}$ Gustavo Capanema Filho foi ministro da Educação e Saúde Pública de 1934 até 1945.
}

RBHM, Vol. 18, nº 35, p. 55-72, 2018 
encontrava, destacando a evolução do curso que ministrava de Geometria Superior e ainda relembrando as promessas do governo brasileiro em mantê-lo no cargo. Entretanto, a sua situação somente foi regularizada em fevereiro de 1943, quando foi readmitido em seu cargo (SILVA, 2002, p. 117), tanto que em 1945 o nome de Bassi aparece novamente como responsável pela cadeira de Geometria Superior na FNFi (FÁVERO et al, 1991, p. 67).

Ainda atuando na FNFi, Bassi lecionou um curso de Topologia na USP. Esse curso consta no Anuário de 1958 da Escola de Engenharia de São Carlos, segundo o qual, o matemático ministrou várias conferências sobre Topologia Combinatória na Universidade de São Paulo durante o ano de 1942 (ANUÁRIO, 1959, p. 58).

Ao longo de 1945, Achille Bassi proferiu algumas conferências, entre elas uma aula inaugural dos cursos da Universidade de Minas Gerais, atual Universidade Federal de Minas Gerais (UFMG). Tal palestra gerou uma publicação na Revista Brasileira de Estatística no ano de 1948, intitulada A Matemática Moderna e a necessidade de sua difusão, onde emitiu a ideia de que "as teorias nas quais melhor se exprimiam os caracteres da Matemática atual eram três: a álgebra moderna, a topologia e a lógica matemática" (BASSI, 1961a, p. I). No mesmo ano de 1945 também foi examinador de bancas na USP e na Escola Nacional de Minas e Metalurgia.

Em 1947 Bassi aceitou um convite para lecionar na Faculdade de Filosofia da Universidade de Minas Gerais. Nessa mesma Universidade, o personagem ministrou um curso de Introdução à Matemática Moderna na Escola de Engenharia no ano de 1950 (ANUÁRIO, 1959, p. 58).

Entretanto, ao serem desrespeitadas as cláusulas do seu contrato com a Universidade de Minas Gerais, o matemático foi obrigado a aceitar concomitantemente outro cargo na Escola Nacional de Minas e Metalurgia (BASSI, 1961b, p. 8), incorporada à Universidade do Rio de Janeiro desde 1931 e, consequentemente, à Universidade do Brasil em 1945.

Já em novembro de 1952, o personagem recebeu um convite para organizar e chefiar o Departamento de Matemática da Escola de Engenharia de São Carlos (BASSI, 1961b, p. 9). Ao aceitar o convite, se tornou Chefe do Departamento de Matemática da Escola, contratou professores estrangeiros para atuarem como docentes, organizou uma biblioteca que hoje recebe o seu nome, assumiu de forma definitiva a Cadeira de Geometria e teve participação crucial na criação do Instituto de Ciências Matemáticas de São Carlos (ICMSC) - no ano de 1971 - como membro do Conselho Universitário, tornando-se o primeiro Diretor do mesmo.

Desde sua chegada ao Brasil, Achille Bassi publicou alguns livros que foram classificados como didáticos segundo documento anexo ao processo de contagem de tempo de serviço do mesmo. Eles são: O significado da Escola de Engenharia de São Carlos de 1953, Elementos de Geometria Projetiva de 1954, Elementos de Geometria Projetiva (edição ampliada) de 1966, Noções críticas elementares de topologia geral de 1955, Considerações introdutórias sobre os sistemas lógico-dedutivos de 1956, Problemas educacionais brasileiros de 1963, Discurso por ocasião da cátedra de Geometria de 1963, Galileu Galilei. Conferências Comemorativas de 1965 (PROC. 6366-53, lista 3).

Desta forma, em sua atuação profissional tanto na FNFi como na EESC, Bassi teve participação relevante no cenário da consolidação de um espaço de ensino e pesquisa em 
Matemática no Brasil. Portanto, neste texto, será abordada sua trajetória intelectual e profissional e, consequentemente, sua contribuição para a institucionalização da Matemática nas Universidades nas quais atuou no período entre as décadas de 1930 e 1960.

\section{Achile Bassi no contexto da criação da Faculdade Nacional de Filosofia (FNFi): primeiros passos}

A Universidade do Brasil (UB) foi criada em 1937, a partir da antiga Universidade do Rio de Janeiro e abrangeu, inicialmente, quinze faculdades ou escolas chamadas "nacionais", além de dezesseis institutos e o Museu Nacional (CPDOC, [s.d]).

O objetivo do governo ao criar a UB era "[...] implantar em todo o país um padrão nacional de ensino superior e estabelecer um sistema destinado a controlar a qualidade desse ensino" (CPDOC, [s.d]). Além disso:

"[...] apesar de enfatizar o aspecto democratizante do ensino universitário, o ministro Capanema criou uma universidade claramente destinada às elites. Nessa perspectiva se incluía o projeto grandioso de construção da Cidade Universitária, que pretendia ser o núcleo da cultura brasileira. As obras, no entanto, não chegaram a ser iniciadas na gestão de Capanema" (CPDOC, [s.d]).

Essa posição de Gustavo Capanema Filho também foi apresentada no livro Tempos de Capanema, onde os autores ao citarem uma entrevista concedida pelo próprio ministro, concluíram que "[...] para ele, era mais importante o preparo das elites do que a alfabetização intensiva das massas" (SCHWARTZMAN et al, 2000, p. 221).

Em 1939 foi fundada a Faculdade Nacional de Filosofia (FNFi), sendo uma das unidades da Universidade do Brasil. Esta "[...] faculdade estava organizada em quatro seções fundamentais: Filosofia, Ciências, Letras e Pedagogia", além da "[...] seção especial de Didática" (FERREIRA, 2012, p. 614) e, tinha como objetivo "[...] preparar trabalhadores intelectuais para o exercício de atividades culturais de ordem desinteressada ou técnica, bem como formar candidatos ao magistério de nível secundário e normal" (FERREIRA, 2012, p. 614).

Com a criação da FNFi fez-se necessária a contratação de docentes para a nova instituição. De acordo com Marieta de Moraes Ferreira (2012, p. 615), o recrutamento de docentes para atuarem na FNFi baseava-se nas redes de relações dos candidatos. Esta informação corrobora com as afirmações de Fávero (1991 et al, p. 63), o qual explica que as contratações de professores estrangeiros para atuarem na Faculdade Nacional de Filosofia foram realizadas pessoalmente pelo Ministro da Educação e Saúde, Gustavo Capanema, se não pessoalmente, por intermédio dele. Circe Mary Silva da Silva (2002, p. 107), também faz essa constatação ao dizer que "[...] a chegada dos matemáticos italianos no Rio de Janeiro concretizou-se pelos canais oficiais, mais precisamente pelos contatos da embaixada brasileira diretamente com a embaixada italiana". Schwartzman (2000 et al, p. 
231) relata o recrutamento dos profissionais da seguinte forma: "Em junho de 1939 o embaixador italiano no Brasil, Ugo Sola, confirma por carta haver o governo brasileiro pedido ao governo italiano a designação de professores de língua e literatura italiana, análise matemática, mecânica racional, física teórica, físico-química, química, geometria superior e física experimental".

Um dos docentes contratados para atuar na FNFi foi Achille Bassi, como já mencionado anteriormente. E o fato do matemático citado ter vindo de instituições reconhecidas da Itália $^{2}$ e por já ter estudado no Instituto de Estudos Avançados de Princeton $^{3}$, favoreceu o contato do mesmo com diferentes tratamentos ou abordagens da própria matemática. E, esse encontro de pesquisadores ou docentes no âmbito internacional, fomentou a troca de ideias e discussões, contribuindo com a circulação dos estudos em voga daquele período. Por conseguinte, a contratação tanto de Achille Bassi como de outros professores estrangeiros ${ }^{4}$ para atuarem no Brasil, cooperou com essa circulação do conhecimento matemático e, consequentemente, com a institucionalização da mesma no país. Neste sentido, podemos destacar a publicação, em 1936, da primeira revista dedicada a trabalhos de pesquisa em Matemática - o Jornal de Matemática Pura e Aplicada da Universidade de São Paulo - criada e dirigida pelo matemático italiano Luigi Fantappiè 5 (1901-1956) (SILVA, 2003, p. 135).

Entretanto, com o início da Segunda Guerra Mundial e posterior cancelamento dos contratos de professores italianos que aqui residiam e que atuavam na $\mathrm{FNFi}$, muitos docentes contratados para atuarem no Brasil, tanto na Faculdade de Filosofia como também na Universidade de São Paulo (USP), retornaram a seus países de origem. Durante esse período, Achille Bassi permaneceu no Brasil e, com o seu contrato de trabalho cancelado, passou por algumas dificuldades financeiras (DAMIÃO, 2014).

Apesar dos problemas enfrentados pelos docentes da Faculdade Nacional de Filosofia, ao analisarmos as contribuições da instituição, não podemos deixar de mencionar que "[...] a FNFi formou gerações de professores de diversas áreas e foi um marco para o desenvolvimento cultural, científico e tecnológico do país. Passaram pela instituição, desde sua fundação em 1939, professores brasileiros e estrangeiros que contribuíram para a institucionalização de seus respectivos campos de conhecimento" (FERREIRA, 2012, p. 614). Além de contribuir com a vinda de quinze professores estrangeiros e,

\footnotetext{
${ }^{2}$ Escola Normal Superior de Pisa: Achille Bassi terminou o curso superior de Matemática na Escola Normal Superior de Pisa no ano de 1929. Universidade de Roma: no ano de 1930, o matemático foi nomeado assistente do Professor Francesco Severi (1879-1961) da Universidade de Roma. Universidade de Turim: após aprovação em concurso, no ano de 1933, Bassi foi nomeado assistente na Universidade de Turim. Universidade de Bolonha: matemático foi nomeado professor interino na Universidade de Bolonha no ano de 1938, assumindo primeiramente a Cadeira de Geometria Descritiva e Complementes de Projetiva e, no ano seguinte, a Cadeira de Geometria Superior (BASSI, 1961b, p. 5).

${ }^{3}$ Entre os anos de 1936 e 1937, o matemático permaneceu na Universidade de Princeton na categoria de Professor Visitante.

${ }^{4}$ Entre as décadas de 1930 e 1950 chegaram para trabalhar na FNFi os seguintes matemáticos italianos: Gabrielle Mammana, Luigi Sobrero, Achille Bassi e Alejandro Terracini (SILVA, 2003, p. 137).

${ }^{5}$ Luigi Fantapierè (1901-1956): matemático italiano contratado para a Cátedra de Geometria Superior na Faculdade de Filosofia, Ciências e Letras da USP. Fantapierè introduziu o conceito de funcional analítico e trouxe suas ideias para o Brasil, onde teve inúmeros discípulos (D’AMBROSIO, 2008, p. 74).
} 
consequentemente, com a circulação do conhecimento naquele período. Dentre os professores contratados, destacamos, mais uma vez, Achille Bassi que permaneceu em solo brasileiro e contribuiu juntamente com outros personagens e instituições com o processo de institucionalização da Matemática no país.

Na Faculdade Nacional de Filosofia, além de ministrar as disciplinas de Geometria Superior e Complementos de Geometria (SILVA, 2002, p. 110), o personagem também organizou um curso de extensão bienal no qual um de seus alunos foi Leopoldo Nachbin ${ }^{6}$ (1922-1993) que, inclusive, realizou um trabalho sob a orientação de Bassi (BASSI, 1961b, p. 6).

Ainda na $\mathrm{FNFi}$, o matemático elaborou um projeto para a criação de uma biblioteca orientada à investigação em Matemática, entretanto, mesmo sendo aprovado pela Congregação da Instituição, o mesmo foi recusado em análises administrativas posteriores e não foi colocado em prática (BASSI, 1961b, p. 7).

\section{Bassi e a expansão para o interior paulista da Universidade de São Paulo: A Escola de Engenharia de São Carlos (EESC)}

A Universidade de São Paulo foi criada em 1934 por meio do Decreto Estadual $\mathrm{n}^{\circ} 6283$. Entre os objetivos da criação dessa Universidade, citados no artigo primeiro do referido decreto, estavam: a promoção da pesquisa e o progresso da ciência, além de formar especialistas, técnicos e profissionais em todas as áreas, tanto científica como artística. "A universidade teria autonomia administrativa e acadêmica, destinando-se a criar uma nova elite que assumisse a liderança do país, superando o atraso e levando São Paulo de volta ao lugar que merecia como o estado líder da federação" (SCHWARTZMAN, 2001, c. 5, p. 23).

Juntamente com a Universidade de São Paulo, foi fundada a Faculdade de Filosofia, Ciências e Letras (FFCL/USP) que tinha como finalidade "[...] integrar a USP e atuaria como um centro catalisador das demais unidades da universidade" (SILVA, 2007, p. 572). A FFLC/USP foi então criada para ser o centro da mais nova Universidade, por onde passariam personagens que contribuíram para as diversas áreas do conhecimento humano.

Naquele momento, o Brasil vivenciava a escassez de profissionais capacitados para executarem o projeto político-pedagógico dessa nova Faculdade de Filosofia, Ciências e Letras. Foi necessário então buscar professores europeus que dominassem não somente os conteúdos das disciplinas, mas também os métodos de lecionar (BARROS, 1984, p. 12 apud FÁVERO et al, 1991, p. 61). O primeiro diretor da FFCL, o Professor Theodoro Augusto Ramos ${ }^{7}$ (1895-1937), foi designado pelo governo de São Paulo a ir até a Europa contratar pessoalmente tais profissionais. Os países de origem destes docentes iniciais foram Itália, França e Alemanha, sendo que, a Primeira Missão Estrangeira de professores da USP, contou com treze profissionais, dos quais quatro eram italianos, seis franceses e

\footnotetext{
${ }^{6}$ Considerado um importante matemático brasileiro, membro fundador do CBPF (Centro Brasileiro de Pesquisas Físicas) e do IMPA (Instituto Nacional de Matemática Pura e Aplicada).

${ }^{7}$ Engenheiro Civil e Doutor em Ciências Físicas e Matemáticas, além de Professor da Escola Politécnica.
}

RBHM, Vol. 18, nº 35, p. 55-72, 2018 
três alemães, que buscaram contribuir para a consolidação da USP em seus primeiros anos de funcionamento.

O personagem matemático aqui tratado, Achille Bassi, também chegou a lecionar esporadicamente na USP. Na década de 1940, quando era docente da FNFi, ministrou um curso de Topologia na FFCL (BASSI, 1961b, p. 7 - 8) e algumas conferências sobre Topologia Combinatória (ANUÁRIO, 1959, p. 58). E, com a saída de Giacomo Albanese ${ }^{8}$ (1890-1956) da universidade, também atuou como docente da disciplina de Geometria Superior na Faculdade de Filosofia Ciências e Letras (SILVA, 2002, p. 117).

Após a criação da FFCL/USP e FNFi/UB começamos a ver indícios da formação de uma comunidade matemática brasileira e de um início de institucionalização desta área de pesquisa, pois no ano de 1945 criou-se, com a participação dos professores estrangeiros que aqui residiam, a Sociedade Matemática de São Paulo. Segundo Lucieli M. Trivizoli (2008, p. 94): “Ao reconstituir a história da Sociedade de Matemática de São Paulo percebeu-se que suas atividades e publicações influenciaram a integração da comunidade matemática brasileira. Permitiu a consolidação das pesquisas realizadas no Brasil, bem como dos centros de pesquisas".

Ainda sobre a fundação da Sociedade, Ubiratan D'Ambrosio (2008, p. 82) acrescentou:

\begin{abstract}
“(...) e iniciou-se a publicação do Boletim da Sociedade de Matemática de São Paulo. Essa revista, que se tornou internacionalmente reconhecida, publicou, em seus 18 fascículos, 77 artigos, alguns sendo traduções de artigos importantes publicados no exterior. A Sociedade de Matemática de São Paulo foi extinta em Assembléia Geral Extraordinária em 1972, sendo, em 1969, fundada a Sociedade Brasileira da Matemática."
\end{abstract}

Desta forma, diante da criação e posterior expansão da Universidade de São Paulo, a formação de sociedades científicas de Matemática e também de revistas periódicas com o intuito de publicar as pesquisas matemáticas que estavam em desenvolvimento, a década de 1940 pode ser considerada a "[...] precursora do período de efervescência para a consolidação da pesquisa matemática em nosso país" (SILVA, 2007, p. 578),

Nesta mesma perspectiva, o ano de 1948 também foi um marco importante para a fundação de alicerces que suportariam mais à frente a criação de um espaço de ensino e pesquisa em Matemática no Brasil. Em 24 de setembro, o Decreto-Lei no 161 criou mais três instituições subordinadas à USP: Faculdade de Medicina de Ribeirão Preto, Faculdade de Farmácia e Odontologia de Bauru e a Escola de Engenharia de São Carlos (EESC/USP); esta última de maior relevância para a matemática.

\footnotetext{
${ }^{8}$ Giàcomo Albanese (1890-1956): matemático italiano que foi contratado para atuar na Faculdade de Filosofia, Ciências e Letras da USP no ano de 1936 por indicação de Luigi Fantappiè. Antes de vir para o Brasil, Albanese já tinha se projetado internacionalmente por seus trabalhos sobre variedades algébricas que, a partir da década de 1960, tornou-se um elemento importante no estudo de Geometria Algébrica Moderna (D’AMBROSIO, 2008, p. 74).
} 
Essa expansão da USP, ocorrida após a Segunda Guerra Mundial, enfrentou, a princípio, resistência dos próprios docentes, tanto que o projeto foi analisado e reprovado pelo Conselho Universitário em 19 de dezembro de 1947. Após ser redigido novamente, foi vetado pelo Governador Lucas Nogueira Garcez (1913-1982) em 10 de setembro de 1948, mas, a Assembleia Legislativa rejeitou o veto e, finalmente, a Lei de criação das unidades da USP no interior de São Paulo foi aprovada pelo Presidente da Assembleia Legislativa Lincoln Feliciano da Silva (EESC, [s.d.]a).

Embora a criação da EESC tenha sido aprovada em 1948, apenas em 16 de dezembro de 1952, com a promulgação da Lei $n^{\circ} 1968$, foram estabelecidas estrutura, organização didática, quadro de pessoal e outras providências para a Escola. A lei previa que a Escola ofereceria o curso fundamental com duração de dois anos, dois cursos normais com duração de três anos que seriam o de Engenharia Mecânica e o de Engenharia Civil, além de cursos de aperfeiçoamento, especialização e doutorado. Também foram apresentadas as matrizes de disciplinas de cada curso e o agrupamento das disciplinas em Cadeiras Simples e Cadeiras Reunidas. O corpo docente devia ser composto por professores catedráticos, professores adjuntos, assistentes e instrutores, além de livres-docentes e assistentes contratados por tempo determinado para algum curso ou trabalho especial. Ainda estipulava as atribuições de cada cargo docente e algumas regras do regime de tempo integral (BRASIL, 1952).

Após obter a licença de funcionamento no dia 10 de março de 1953, a EESC teve suas atividades iniciadas como nova integrante da USP no dia 18 de abril na casa D'Itália, um prédio situado na Rua Nove de Julho, centro da cidade de São Carlos. Essa construção pertencia à Sociedade Dante Alighieri e foi cedida por dez anos para as atividades da Escola em caráter provisório, até que fosse construído o prédio definitivo na área doada pela Prefeitura da cidade (EESC, [s.d]b).

A criação da Escola de Engenharia e até mesmo sua palestra inaugural ministrada no dia 18 de abril de 1953 pelo então governador do Estado de São Paulo - Lucas Nogueira Garcez (1913-1982), caracterizam o momento vivido na América Latina entre os anos de 1930 e 1950, em que surgiram “[...] expectativas para um desenvolvimento acelerado da ciência, como parte dos projetos econômicos desenvolvimentistas" (SALDAÑA, 2000, p. 15). Deste modo,

“[...] não foi difícil perceber a relação entre as preocupações desenvolvimentistas do Brasil no pós-guerra e o plano pedagógico da Escola, sobretudo no que diz respeito às pesquisas tecnológicas. Mais evidente, ainda, foi a relação entre a preocupação do Estado em desenvolver o interior e a própria criação da Escola de Engenharia de São Carlos” (BUFFA; NOSELLA, 2000, p. 20).

Esse momento de incentivo ao avanço econômico e científico vivido pelo Brasil após a Segunda Guerra Mundial, pode ser verificado resumidamente na análise de Videira,

"Para esses dois últimos países [Brasil e Argentina], (...), a questão que se colocava dizia respeito à "súbita" conscientização que setores das 
suas intelectualidade e elite político-acadêmica passaram a mostrar para com o fato de que a ciência transformara-se no principal fator de desenvolvimento econômico. Sem ciência, não haveria chance para país algum chegar a ser considerado desenvolvido. Até aquela data, a ciência era personagem relativamente desconhecida e esquecida para a grande maioria da população mundial, que se encontrava nos países que não integravam o círculo pequeno das nações mais poderosas." (VIDEIRA, 2004 , p. $281-282$ ).

Seguindo essa mesma perspectiva de incentivo ao avanço científico, o matemático Achille Bassi foi convidado para organizar o Departamento de Matemática e lecionar na nova instituição (Escola de Engenharia de São Carlos) no final do ano de 1952. O referido convite partiu do então diretor da Escola, o Professor Theodoreto de Arruda Souto (BASSI, 1961b, p. 9), que lhe foi apresentado pelo Professor José Octavio Monteiro de Camargo, engenheiro mecânico-eletricista, professor da Escola Politécnica da USP e amigo pessoal de Theodoreto.

Ao convidar o personagem para atuar na Escola de Engenharia, o diretor da instituição estaria seguindo as orientações da própria USP que:

"[...] recomendavam uma rigorosa seleção de docentes, com nível científico elevado e atualizado, uma grande preocupação com a pesquisa e com a carreira docente e uma assistência à indústria local. Desse modo, a Escola não seria apenas um veículo de divulgação da ciência, mas uma instituição destinada a criar conhecimentos e produzir trabalhos para beneficiar a coletividade" (MENINO, 2001, p. 75).

Buffa e Nosella (2000, p. 38) também mencionaram no livro Escola de Engenharia de São Carlos: os primeiros tempos: 1948 - 1971 essa característica da EESC e do diretor da mesma, relatando que "[...] a determinação do diretor de priorizar a pesquisa científica e técnica não se aplica apenas ao fato de situar-se a Escola numa tranquila cidade do interior. As razões mais importantes foram a vinculação da EESC à Universidade de São Paulo e o clima cultural do pós-guerra, que privilegiava a pesquisa tecnológica”.

Desta forma, ao assumir o cargo de chefe do Departamento de Matemática da Escola de Engenharia, Bassi logo tratou de contratar professores para atuarem na instituição de acordo com as exigências relatadas. Contratou, então, os docentes italianos Jaurès Cecconi ${ }^{9}$ da Universidade de Pisa e Ubaldo Richard ${ }^{10}$ da Universidade de Turim para

\footnotetext{
${ }^{9}$ Jaurès Pacífico Cecconi (1918-2012): matemático italiano, foi laureado pela Universidade de Pisa com distinção entre 1939/1940. No ano de 1940 foi assistente da disciplina de Análise Matemática na Academia Naval de Livorno e da mesma disciplina na Universidade de Pisa no ano seguinte. Também foi responsável por um curso nesta última instituição entre 1947 e 1951 e dos cursos de "Física Matemática" e de "Análise Superior" entre 1952 e 1954. Alcançou o título de livre-docente em Análise Matemática em 1951 também pela Universidade de Pisa e foi contratado por dois anos a partir de setembro de 1954 pela EESC como Professor Adjunto da Cadeira de Cálculo. Já em 1955 assumiu a Cadeira de Mecânica Geral na mesma instituição e seu contrato foi renovado por mais dois anos. Em 1956 assumiu novamente a Cadeira de Cálculo na Escola de Engenharia. Desde 1948 até
} 
atuarem nas cadeiras de Cálculo e Mecânica Geral (ANUÁRIO, 1957, p. 24 - 27; ANUÁRIO, 1959, p. 110 - 112). A admissão por parte de Achille Bassi dos profissionais italianos para assumirem cargos de docentes na EESC, além de outras decisões tomadas pelo matemático à frente do Departamento, nos remetem a uma valorização da circulação de ideias internacionais e de uma fortificação das bases do ensino e pesquisa em Matemática no Brasil, já que um dos primeiros passos no processo de institucionalização desta disciplina já havia sido dado anteriormente com a constituição de uma Sociedade Matemática.

Segundo Buffa e Nosella (2000, p. 40),

"[...] nessa época do pós-guerra, a Europa, com enormes dificuldades, reconstruía tanto seu patrimônio quanto suas finanças, tragicamente abalados. Assim, o êxodo de grandes intelectuais e até mesmo a vinda de obras de arte tornavam-se necessários à Europa e interessantes ao Brasil, que oferecia salários atrativos”.

Entretanto, se por um lado os salários eram atraentes, segundo os autores, por outro, sabemos que a permanência dos docentes estrangeiros era dificultada com a exigência de renovação de títulos, o que talvez tenha propiciado o retorno da maioria deles para seus países de origem. Além disso, em algumas cartas escritas pelo próprio Bassi, encontramos comparações de salários de professores italianos com o dos brasileiros, o que descarta a ideia de salários atrativos para docentes.

Ainda sobre a vinda de matemáticos para o Brasil - no período do pós-guerra - de forma a exemplificar o trecho acima, podemos destacar "[...] o grupo de matemáticos, na sua maioria franceses, de pseudônimo Nicolas Bourbaki" (PIRES, 2006, p. 1). Esse grupo, um dos mais reconhecidos entre os matemáticos, esteve na Universidade de São Paulo por períodos entre os anos de 1945 e 1966 e, seu principal objetivo era "[...] reconstruir o todo da Matemática - clássica e moderna - numa ampla base geral de forma a encerrá-lo como um estudo unificado" (PIRES, 2006, p. 1). A importância desse grupo está relacionada à sua ligação com o Movimento da Matemática Moderna.

Nesse âmbito de intensificação de pesquisas tecnológicas, no ano de 1959 ficou decidido na Organização Europeia de Cooperação Econômica que, ocorreria uma nova versão do currículo de Matemática. E, como a visão matemática vigente era "[...] a estruturalista, pautada nos trabalhos de Bourbaki, esta foi a inspiração para o novo currículo" (ESQUINCALHA, 2012, p. 33). O movimento de reorganização do currículo de

1956, o Professor Cecconi publicou 24 trabalhos, todos em língua italiana e até 1958 alcançou um total de 28 trabalhos publicados (ANUÁRIO, 1957, p. 24 - 27; ANUÁRIO, 1959, p. 61).

${ }^{10}$ Ubaldo Richard: era formado em Ciências Matemáticas desde 1937 e foi nomeado Assistente de Análise Matemática do Instituto Politécnico de Turim em 1938, além de também ser nomeado Professor Adjunto de Análise pelo mesmo Instituto. Em 1953 alcançou o título de livre-docente em Análise Algébrica e Infinitesimal pela Universidade de Turim e foi encarregado de vários cursos nessa Universidade. Também foi colaborador do Instituto Nacional para as aplicações do Cálculo de Roma desde 1953 e assinou contrato com a EESC em 1954 para a Cadeira de Cálculo e em 1956 como Professor Catedrático da Cadeira de Mecânica Geral. Até 1958 tinha vinte e cinco trabalhos publicados e duas conferências ministradas (ANUÁRIO, 1959, p. 110 - 112).

RBHM, Vol. 18, nº 35 , p. 55-72, 2018 
Matemática ocorreu internacionalmente e ficou conhecido como Movimento da Matemática Moderna (MMM). Essa reestruturação "[...] pretendia aproximar a Matemática trabalhada na escola básica com a Matemática produzida pelos pesquisadores da área" (WIELEWSKI, [s.d.], p. 1), o que proporcionou, especialmente no Brasil, o surgimento de grupos de pesquisa preocupados com essa temática (ESQUINCALHA, 2012, p. 33).

Ao mencionar a ênfase dada à pesquisa científica por parte dos dirigentes da Escola de Engenharia, também deve-se ressaltar que, assim que Achille Bassi assumiu seu cargo na Escola de Engenharia, tratou de organizar uma biblioteca orientada à investigação Matemática. A esse respeito, na Tese de Cátedra ${ }^{11}$ de sua autoria encontra-se um agradecimento especial ao professor Souto:

"Ao acabar este trabalho, desejo endereçar meus pensamentos ao Professor Doutor Theodoreto de Arruda Souto, Digníssimo Diretor desta Escola, que não limitou esforços para que o Departamento de Matemática tivesse, desde os primeiros anos de funcionamento da Escola, uma biblioteca condigna, que permitisse um sério trabalho de investigação, e que, sempre, em qualquer circunstância, estimulou na Escola o espírito de pesquisa, ao qual êste trabalho também deve a sua existência." (BASSI, 1961a, p. VI).

O próprio matemático se encarregou de conseguir livros para o acervo da Biblioteca recém-criada:

"Ele lutava pela biblioteca, ia atrás de livros, comprava livros em sebo, tinha amigos livreiros. Era italiano, então tinha conhecidos na Itália [...]. Ele comprava coisas que ninguém pensava em comprar. A biblioteca tem uma coleção de obras clássicas, que são muito valiosas, são coisas importantes, tem obras de 1700 e pouco, livros de Bernoulli. Tem livros raríssimos e coleções de revistas muito boas." (TÁBOAS, 2000). ${ }^{12}$

A constituição da referida Biblioteca além de estar relacionada ao momento pós Segunda Guerra, em que foi dada uma ênfase maior ao desenvolvimento tecnológico do

\footnotetext{
${ }^{11}$ Embora já lecionasse na Cadeira de Geometria da EESC, o personagem resolveu prestar o concurso para assumi-la de forma definitiva. Após o adiamento do concurso, o mesmo ocorreu no dia 1 de agosto de 1961 para provimento efetivo do cargo de Professor Catedrático da Cadeira Reunida $n^{\circ} 12$ (Geometria) que era compreendida pelas disciplinas "Geometria Analítica e Projetiva" e "Complementos de Geometria e Geometria Descritiva". Para provimento da Cadeira, Bassi apresentou a tese A dualidade nas álgebras de Boole topológicas e suas consequências, onde apresenta considerações de álgebra, topologia e lógica. Segundo o matemático, a origem desse tema ocorreu em 1947, quando lecionou o curso de extensão em Topologia na FNFi no Rio de Janeiro. Durante o referido curso, observou que "na teoria da dualidade nos espaços topológicos não havia, no [seu] parecer, uma sistematização satisfatória e, tecendo considerações sobre êste assunto, introdu[ziu], desde aquela época, o conceito de semidualidade, que cham[ou] então de "dualidade condicionada"” (BASSI, 1961a, p. I). E, após a candidatura para a efetivação de seu cargo na EESC, achou oportuno trabalhar com o mesmo tema.

${ }_{12}$ Entrevista de Plácido Zoega Táboas a Ana Ligabue no evento comemorativo dos 30 anos do Instituto. TÁBOAS, Plácido Zoega. Comemoração dos 30 anos do ICMC: Depoiment. [24/03/2000]. Sala do entrevistado ICMC/SC. Entrevista concedida a Ana Ligabue.
} 
país, também está atrelada à formação intelectual do próprio Bassi que, teve sua educação e início de carreira docente na Itália, onde tinha acesso a grandes bibliotecas. E, como a prioridade da própria Escola de Engenharia e de seus membros era a valorização da pesquisa, então, havia a necessidade de um conjunto de obras de qualidade para a consulta dos estudantes e do próprio corpo docente, o que justifica a necessidade da constituição do acervo.

Após a criação do Instituto de Ciências Matemáticas da USP (campus de São Carlos) no ano de 1971, parte das obras do acervo foi transferida para a Biblioteca do novo Instituto passando a ser nomeada como "Biblioteca Achille Bassi". Na atualidade, a quantidade de livros, revistas e periódicos pertencentes à biblioteca cresceu consideravelmente ${ }^{13}$, podendo ser considerada uma das mais importantes do Brasil, já que “[...] possui hoje o terceiro maior acervo do país na área de matemática” (MUNDO BIBLIOTECÁRIO, 2014).

Na década de 1970, Bassi também teve participação crucial na criação do Instituto de Ciências Matemáticas de São Carlos (ICMSC), citado acima, por ser membro do Conselho Universitário. Esse Instituto foi criado no dia 28 de dezembro de 1971, juntamente com o Instituto de Química e Física (IQFSC) pelo Decreto Estadual n ${ }^{\circ} 52850$ (EESC, [s.d]b).

Nas palavras de Arouca, o matemático,

"[...] sem descurar de suas atividades científicas, na qualidade de representante da Egrégia Congregação da Escola de Engenharia de São Carlos, desenvolveu brilhante atividade no Conselho Universitário na época da Reforma, tendo, entre outras realizações, contribuído decisivamente para a criação de mais duas Unidades da USP em São Carlos: o Instituto de Ciências Matemáticas e o de Física e Química" (AROUCA, 1973, p. 5 - 6).

Ainda na mesma década, a área de Matemática da EESC “[...] foi credenciada como Centro Regional pelo Conselho Nacional de Pesquisas para o Mestrado e pela Universidade de São Paulo, para o Mestrado e Doutorado" (MENINO, 2001, p. 105). Entretanto, o curso de doutoramento em Ciências (Matemática) na USP já ocorria anteriormente devido ao decreto do interventor federal do Estado de São Paulo $\mathrm{n}^{\mathbf{o}} 12.511$ de 21 de janeiro de 1942 (SILVA, 2003, p. 143). Já na EESC, o doutorado em Matemática teve início a partir da década de 1950, onde também foi “[...] instituído um forte programa de professores visitantes para ministrar cursos, orientar alunos, realizar seminários e conferências" (SILVA, 2003, p. 145). ${ }^{14}$

\footnotetext{
13 “O espaço agrega hoje aproximadamente 140 mil volumes e 23 mil títulos de periódicos eletrônicos nas áreas de ensino e pesquisa não só de matemática, mas também de computação e áreas afins" (MUNDO BIBLIOTECÁRIO, 2014).

${ }^{14}$ Entre os primeiros doutoramentos realizados Escola de Engenharia de São Carlos, podemos citar o de Ubiratan D’Ambrosio, personagem de destaque nas áreas de Educação Matemática e História da Matemática atualmente, cuja tese intitulou-se Superfícies generalizadas e conjuntos de perímetro finito e defendida no ano de 1963, sob
} 
Os doutoramentos realizados a partir do decreto acima foram os primeiros da área de Matemática no país, já que o Instituto de Matemática Pura e Aplicada (IMPA) “[...] foi também uma das primeiras instituições do país a instituir um programa de doutorado em Matemática", e o mesmo teve início em 1962 (SILVA, 2003, p. 150). Ao analisarmos este período da implantação do doutorado na Universidade de São Paulo e suas leis de instituição do grau de Doutor de 1942 e do novo regimento de 1952, percebemos o início de uma preocupação em formar pesquisadores e docentes brasileiros para atuarem nas instituições de ensino e pesquisa. Pois, os primeiros esforços em contratar professores estrangeiros para semear tais feitos nessa instituição já haviam sido realizados e alguns dos profissionais contratados já tinham retornado a seus países de origem. Além disso, a partir do processo de institucionalização da Matemática como área de pesquisa no Brasil, através da realização de ensino, pesquisa, divulgação e aplicação do conhecimento, começou a ocorrer a formação de grupos de pesquisa que fomentaram a pesquisa científica com uma maior frequência e "[...] a incentivar a formação escolarizada dos jovens estudantes" (SILVA, 2003, p. 147).

Seguindo esta mesma linha, o governo federal, entre o final da década de 1960 e início da década de 1970 ,

"[...] deu início a um forte programa de incentivo financeiro para alunos de pós-graduação, via PICD [Programa Institucional de Capacitação de Docentes], que desejassem concluir sua formação acadêmica. A partir daí professores de várias instituições de ensino do país passaram a se matricular regularmente em programas de mestrado elou doutorado em Matemática” (SILVA, 2003, p. 147).

Esse Programa Institucional de Capacitação de Docentes (PICD) foi fruto dos dois primeiros Planos Nacionais de Pós-Graduação, cujos objetivos destacados em ambos eram: a institucionalização da pós-graduação, a formação de recursos humanos de alto nível e a melhoria da qualidade dos cursos de pós-graduação (BRASIL, 1986, p. 193), o que reforça nossa afirmação de uma maior preocupação na formação de profissionais capacitados para atuarem como novos docentes.

Diante do exposto acima, na década de 1960, sob a direção de Achille Bassi, o Departamento de Matemática da EESC já demonstrava seus primeiros resultados, pois segundo o próprio matemático "produziu entre 1955-1960 mais de vinte trabalhos científicos, dos quais a metade aproximadamente de autoria de jovens capazes que aqui se educaram" (BASSI, 1961b). Nos anos seguintes, o Departamento começou a produzir ainda mais até o seu desmembramento em Instituto de Matemática, tornando-se uma referência até os dias atuais.

orientação de Jaurès Cecconi (VALENTE, 2007, p. 55), um dos matemáticos vindos da Itália para lecionar na instituição. 


\section{Considerações finais}

Neste estudo buscamos discutir o contexto da criação de duas instituições brasileiras (FNFi e EESC), objetivando apontar alguns elementos contribuintes com o desenvolvimento da institucionalização da área da Matemática no Ensino Superior brasileiro. Para isso, utilizamos da figura de um personagem que atuou decisivamente neste processo desde sua chegada ao Brasil em 1939 até seu falecimento no ano de 1973, passando por instituições de ensino de diferentes estados brasileiros. Logo, o mesmo insere-se no período citado por Mariana Cavalari (2012, p. 5), "[...] no decorrer dos anos de 1940, 50 e 60, se organizaram para a criação de Sociedades, periódicos científicos e, também, de centros de pesquisas que promoveram a produção e a divulgação científica, especificamente matemática, em Território nacional", ou seja, o matemático aqui tratado se enquadra nesse período de formação e institucionalização de uma comunidade científica matemática brasileira.

Desta forma, Achille Bassi deve ser visualizado como um elemento contribuinte com o desenvolvimento e institucionalização da Matemática no Brasil na primeira metade do século XX. Pois, a circulação do personagem em instituições internacionais, através de seus contratados e dos estudantes da Escola de Engenharia de São Carlos, acarretou na circulação e intercâmbio de ideias, bem como de discussões sobre a Matemática no período, sendo estes considerados, "[...] um dos aspectos mais significativos do desenvolvimento das ciências. Examinando-se a história das ciências e da tecnologia, os contatos entre pesquisadores constituem uma dimensão extraordinariamente relevante de suas atividades" (GUNTAU; FIGUEIRÔA, 2000, p. 7).

Sua permanência no Brasil e sua atuação na organização do Departamento de Matemática e Instituto de Ciências Matemática da USP de São Carlos, além da introdução de alunos à iniciação em pesquisa, também provocaram, juntamente com a participação de outras unidades de ensino da época e de outras personalidades, mudanças significativas no contexto brasileiro do ensino-pesquisa desta disciplina, o que nos leva a caracteriza-lo como um incentivador da Matemática no período.

A atuação do personagem como professor e na produção de material didático, além das decisões tomadas em relação a gestão do Departamento de Matemática - como a contratação de professores, a organização de grades de disciplina, o contato com outros centros de pesquisa, entre outros-, na organização, fundação e manutenção de uma Biblioteca e empenho na criação de um Instituto de Ciências Matemáticas contribuiram com a formação de outras personalidades e membros para a comunidade matemática brasileira que foi se institucionalizando ao longo do período tratado neste artigo.

\section{Bibliografia}

Fontes documentais

RBHM, Vol. $18, \mathrm{n}^{\mathrm{o}} 35$, p. $55-72,2018$ 
Anuário Da Escola De Engenharia De São Carlos - 1956. 1957. São Carlos, Universidade de São Paulo.

Anuário Da Escola De Engenharia De São Carlos - 1958. 1959. São Carlos, Universidade de São Paulo.

AROUCA, Morenci. 1973. Discurso pronunciado nos funerais do Professor Achille Bassi, São Carlos.

BASSI, Achille. A dualidade nas álgebras de Boole topológicas e suas consequências. 1961a. São Carlos, USP/Escola de Engenharia de São Carlos. [Tese de concurso à Cadeira $\mathrm{n}^{\circ} 12$ - Geometria].

BASSI, Achille. 1961b. Memorial: Referente à formação intelectual, à vida e à atividade profissional ou científica do candidato, Prof. ACHILLE BASSI.

BRASIL. Lei $n^{\circ} 1968$, de 16 de dezembro de 1952. Estabelece a estrutura, a organização didática e o quadro do pessoal da Escola de Engenharia de São Carlos da Universidade de São Paulo, criada por Lei estadual n. 161, de 24 de setembro de 1948, e dá outras providências. Diário Oficial do Estado de São Paulo.

Disponível em: <http://www.al.sp.gov.br/repositorio/legislacao/lei/1952/lei-196816.12.1952.html>. Acesso em: set/2018.

BRASIL. Ministério da Educação e Cultura, Secretaria de Educação Superior/Coordenação de Aperfeiçoamento de Pessoal de Nível Superior, (1986). III Plano Nacional de PósGraduação: 1986-1989. Brasília: MEC/SESU/CAPES.

CPDOC. Diretrizes do Estado Novo (1937 - 1945), Universidade do Brasil.

Disponível em: https://cpdoc.fgv.br/producao/dossies/AEraVargas1/anos3745/EducacaoCulturaPropaganda/UniversidadeBrasil >. Acesso em: set/2018.

DAMIÃO, Ada Sacchi Bassi. Achille Bassi como professor, pesquisador, divulgador e gestor da Matemática no Brasil: Depoiment. [15/02/2014]. Brasília: Entrevista concedida a Aline Leme da Silva.

EESC. Cronologia.

Disponível em:

http://www.eesc.usp.br/portaleesc/index.php?option=com_content $\&$ view $=$ article\&id= $252 \&$ Itemid=396>. Acesso em: set/2018.

EESC. Linha do Tempo.

Disponível em: <http://www.eesc.usp.br/60anos/?page_id=282>. Acesso em: set/2018.

MUNDO BIBLIOTECÁRIO. Evento no ICMC marca 40 anos da Biblioteca Achille Bassi. Disponível em: <http://mundobibliotecario.com.br/2014/09/11/evento-no-icmc-marca-40anos-da-biblioteca-achille-bassi/>. Acesso em: set/2018.

PROCESSO USP 6366/53. São Carlos.

TÁBOAS, Plácido Zoega. Comemoração dos 30 anos do ICMC: Depoiment. [24/03/2000]. Sala do entrevistado ICMC/SC. Entrevista concedida a Ana Ligabue.

Bibliografia 
BELTRAN, Maria Helena Roxo; SAITO, Fumikazu; TRINDADE, Lais dos Santos Pinto. 2014. História da Ciência para formação de professores, São Paulo, Editora Livraria da Física.

BUFFA, Ester; NOSELLA, Paolo. 2000. Escola de Engenharia de São Carlos: os primeiros tempos: 1948-1971, São Carlos, EdUFSCar.

CAVALARI, Mariana Feiteiro. 2012. As contribuições de Chaim Samuel Hönig para o desenvolvimento da matemática brasileira. 202 f. Tese (doutorado em Educação Matemática) - Instituto de Geociências e Ciências Exatas, UNESP, Rio Claro.

D’AMBROSIO. Ubiratan. 2008. Uma história concisa da matemática no Brasil. São Paulo, Editora Vozes.

DANTES, Maria Amélia M.; HAMBURGER, Amélia Império. 1996. A Ciência, os Intercâmbios e a História da Ciência: Reflexões sobre a Atividade Científica no Brasil. In: HAMBURGER, Amélia Império (Org.). A Ciência nas relações Brasil-França (18501950), São Paulo, EDUSP/ FAPESP.

ESQUINCALHA, Agnaldo da Conceição. 2012. Nicolas Bourbaki e o Movimento da Matemática Moderna. Revista de Educação, Ciências e Matemática, v. 2, n. 3, p.28-37.

FÁVERO, Maria de Lourdes de Albuquerque; PEIXOTO, Maria do Carmo de Lacerda; SILVA, Ana Elisa Gerbasi. 1991. Professores Estrangeiros na Faculdade Nacional de Filosofia, RJ (1939-1951). Cadernos de Pesquisa. São Paulo, n. 78, p. 59-71.

FERREIRA, Marieta de Moraes. 2012. O ensino de história na Faculdade Nacional de Filosofia da Universidade do Brasil. Revista História, Ciência, Saúde-Manguinhos. Rio de Janeiro, v. 19, n. 02, p.611-636.

GUNTAU, Martin; FIGUEIRÔA, Silvia F. M. 2000. Apresentação. In: FIGUEIRÔA, S. (Org.). Um olhar sobre o passado: história das ciências na América Latina, Campinas: Ed. da Unicamp.

HOSTINS, Regina Célia Linhares. 2006. Os Planos Nacionais de Pós-graduação (PNPG) e suas repercussões na Pós-graduação brasileira. PERSPECTIVA, Florianópolis, v. 24, n. 1, p. 133-160.

MENINO, Fernanda dos Santos. 2001. A Escola de Engenharia de São Carlos e a criação de um Curso de Matemática. 162f. Dissertação (Mestrado em Educação Matemática) Instituto de Geociências e Ciências Exatas, UNESP, Rio Claro.

PESTRE, Dominique. 1996. Por uma história social e cultural das ciências: novas definições, novos objetos, novas abordagens. Cadernos IG/UNICAMP, v. 6, n. 1, p. 3- 54.

PETITJEAN, Patrick. 1996. Ciências, Impérios, Relações Científicas Franco-brasileiras. In: HAMBURGER, Amélia Império et al. (Org.). A Ciência nas relações Brasil-França (18501950), São Paulo, EDUSP/FAPESP.

PIRES, Rute da Cunha. 2006. A Presença de Nicolas Bourbaki na Universidade de São Paulo. Tese (Doutorado em História da Ciência) - Pontifícia Universidade Católica de São Paulo.

SALDAÑA, Juan José. 2000. Ciência e identidade cultural: a história da ciência na América Latina. In: FIGUEIRÔA, S. (Org.). Um olhar sobre o passado: história das ciências na América Latina. Campinas: Ed. da Unicamp, p. 11-31.

SCHWARTZMAN, Simon; BOMENY, Helena Maria Bousquet; COSTA, Vanda Maria Ribeiro. 2000. Tempos de Capanema, São Paulo, Paz e Terra/ Fundação Getúlio Vargas. 
SILVA, Circe Mary Silva. 2002. Formação de Professores e Pesquisadores de Matemática na Faculdade Nacional de Filosofia. Cadernos de Pesquisa, n. 117, p. 103-126.

SILVA, Clóvis Pereira. 2003. A Matemática no Brasil: História de seu desenvolvimento. 3. ed. São Paulo, Edgar Blücher.

SILVA, Clóvis Pereira. 2007. Visão Panorâmica sobre o Desenvolvimento da Matemática no Brasil. In: LINTZ, R. G. História da Matemática. v. 2. Campinas, Unicamp, Centro de Lógica, Epistemologia e História da Ciência.

TRIVIZOLI, Lucieli Maria. 2008. Sociedade de Matemática de São Paulo: Um estudo histórico institucional. Dissertação de Mestrado (Mestre em Educação Matemática) Programa de Pós-Graduação em Educação Matemática, UNESP, Rio Claro.

VALENTE, Wagner R.(org.). 2007. Ubiratan D'Ambrósio, São Paulo, Annablume.

VERGARA, Moema de Rezende. 2004. Ciência e modernidade no Brasil: a constituição de duas vertentes historiográficas da ciência no século XX. Revista da SBHC, v.2, n.1, p.2231 .

VIDEIRA, Antonio Augusto dos Passos. 2007. Historiografia e história da ciência. ESCRITOS, n.1, p. 111-158.

VIDEIRA, Antonio Augusto Passos. 2004. Transdisciplinaridade, interdisciplinaridade e disciplinaridade na história da ciência. Revista Scientiae Studia, v. 2, n. 2, p. 279 - 293.

WIELEWSKI, Gladys Denise. O Movimento da Matemática Moderna e a formação de grupos de professores de Matemática no Brasil.

Disponível em: < http://www.apm.pt/files/_Co_Wielewski_4867d3f1d955d.pdf>. Acesso em: set/2018.

\begin{tabular}{l}
\hline Aline Leme Silva \\
SESI - Santo André - Brasil \\
Mestre em Ensino, História e Filosofia das Ciências e da \\
Matemática - UFABC / Santo André - Brasil \\
E-mail: aline_leme@ yahoo.com.br \\
Márcia Helena Alvim \\
Centro de Ciências Naturais e Humanas - Universidade \\
Federal do ABC - UFABC - Santo André - Brasil \\
E-mail: marcia.alvim@ufabc.edu.br \\
\end{tabular}

